\title{
Carpal tunnel syndrome: state-of-the-art review
}

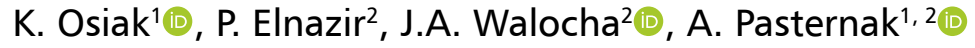 \\ ${ }^{1}$ Department of Plastic Surgery, Medical Centre for Postgraduate Education, \\ Professor W. Orlowski Memorial Hospital, Warsaw, Poland \\ ${ }^{2}$ Department of Anatomy, Jagiellonian University Medical College, Krakow, Poland \\ [Received: 21 September 2021; Accepted: 21 October 2021; Early publication date: 9 November 2021]
}

\begin{abstract}
Carpal tunnel syndrome is the most common peripheral nerve entrapment encountered worldwide. The aetiology can be related to repetitive exposure to vibrations or forceful angular motions, genetic predisposition, injury and specific conditions, such as diabetes, pregnancy and morbid obesity. This entity is observed with increased frequency in females and the elderly. The diagnosis is largely clinical and suspected when patients present with typical symptoms such as numbness, tingling, nocturnal paraesthesia and/or neuritic "pins-and-needles" pain in the radial 3.5 digits. Certain provocative manoeuvres can be employed to evoke the symptoms of the disease to guide the diagnosis. Further testing such as electrodiagnostic studies, ultrasound or magnetic resonance imaging is required in the case of diagnostic uncertainty or if there is a need for objective evaluation whether or not more invasive surgical intervention is required. If the presenting symptoms are mild and discontinuous, non-surgical measures are indicated. However, if the symptoms are moderate to severe, further testing modalities such as nerve conduction studies or needle electromyography are used to determine whether carpal tunnel syndrome is acute or chronic. If significant evidence of axonal injury is identified, surgical treatment may be indicated. Surgical release of the carpal tunnel has evolved over time to become the most common hand surgery procedure. (Folia Morphol 2022; 81, 4: 851-862)
\end{abstract}

Key words: carpal tunnel syndrome, entrapment neuropathy, median nerve, open carpal tunnel release

\section{INTRODUCTION}

Carpal tunnel syndrome (CTS) is the most frequently occurring entrapment neuropathy encountered by plastic, hand and upper extremity surgeons [57]. The aetiology of CTS can be related to work, lifestyle, injury, or genetic predisposition. Repetitive exposure to vibrations or forceful angular motions are thought to be the most common causes of CTS and specific diseases, such as diabetes, pregnancy and morbid obesity may also be associated with an increased risk for the development of CTS [25, 28]. However, it is also seen with increased frequency in females and the elderly population [80]. The diagnosis of CTS is largely clinical and is suspected when patients present with typical symptoms such as numbness, tingling, nocturnal paraesthesiae and/or neuritic "pins-and-needles" pain in the radial 3.5 digits [8]. Further testing is required when there is uncertainty in the diagnosis or an objective measure is required to gauge the need for more invasive interventions such as surgery. Examples of these tests include the electrodiagnostic studies (EDX) such as nerve conduction studies (NCS) 
and electromyography (EMG) [32]. Moreover, certain manoeuvres can be employed to provoke the symptoms of CTS to guide the diagnosis [48]. The first step in the management of CTS is to ascertain whether surgical or non-surgical, more conservative treatment is required. If the presenting symptoms are mild and discontinuous, non-surgical measures are indicated. However, if the symptoms are moderate-to-severe further testing, such as NCS or needle EMG are used to determine whether CTS is acute or chronic and if there is significant evidence of axonal injury. Surgical decompression of the carpal tunnel and its contents was first described by Galloway in 1924 [3] and was later made more popular by Phalen. Over time carpal tunnel decompression has evolved to become the most common hand surgery procedure.

\section{ANATOMY OF THE CARPAL TUNNEL}

Carpal tunnel is a restricted, rigid passage located on the palmar surface of the wrist. It is formed anteriorly by the flexor retinaculum with its central segment measuring 2-4 $\mathrm{mm}$ in thickness that is often referred to as the transverse carpal ligament (TCL). The posterior aspect is limited by the volar surface of the carpus, which is concave and forms the so called carpal sulcus. The lateral border of the carpal sulcus is formed by the radio-carpal eminence which consists of the tubercles of the scaphoid and trapezium bones and the medial border is formed by the tubercles of the pisiform and hook of the hamate bones; the socalled ulnar carpal eminence. The most proximal part of the carpal tunnel begins on the volar surface of the wrist crease and then runs distally extending from the lateral border of the thumb in abduction to the level of the hook of the hamate; a landmark that is often referred to as Kaplan's cardinal line [71]. The carpal tunnel protects the median nerve and 9 tendons that act to flex the fingers: 1 tendon of flexor pollicis longus (FPL), 4 tendons of flexor digitorum profundus (FDP) and 4 tendons of flexor digitorum superficialis (FDS) muscles. The nerve is the most superficial structure and overlies the FDS and FDP tendons to the index finger (Fig. 1). The median nerve enters the volar surface of the hand through the carpal tunnel which runs under the flexor retinaculum. In the palm of the hand, the median nerve branches off into muscular branches which supply the thenar muscles (the abductor pollicis brevis muscle, the opponens pollicis muscle and superficial head of the flexor pollicis brevis muscle) and the two lateral lumbricals, finally termi-

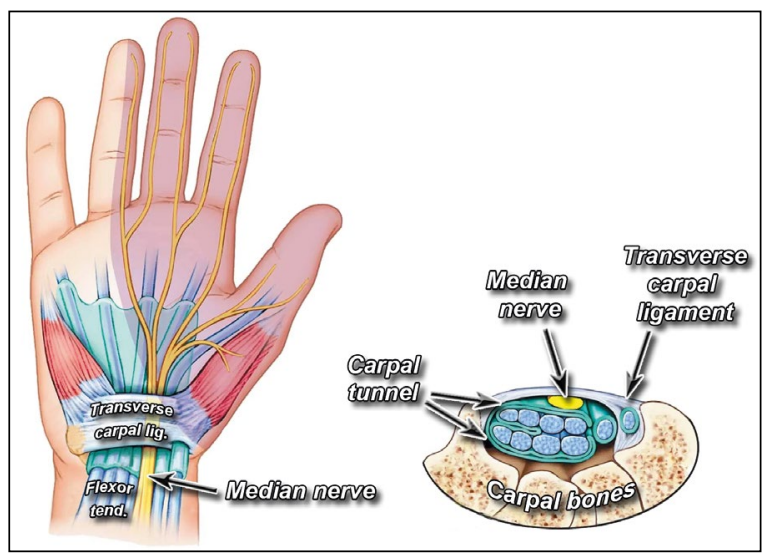

Figure 1. Anatomy of the carpal tunnel.

nating as three common palmar nerves to the digits, which subsequently divide further into the proper palmar digital cutaneous nerves innervating the volar surface of the index finger, middle finger, and one-half of the ring finger [30]. The palm of the hand receives sensory innervation by the palmar cutaneous branch of the median nerve (PCBMN). PCBMN branches off the median nerve approximately $6 \mathrm{~cm}$ proximal to the $\mathrm{TCL}$, then passes superficially to the ligament which means this branch is independent of any pressure fluctuations within the carpal tunnel. When dividing the transverse carpal ligament to approach the deep structures in the carpal tunnel, the median nerve and its branches deserve special attention. The motor branch of the median nerve usually becomes recurrent at the distal margin of the transverse carpal ligament before entering the thenar musculature, i.e. regular recurrent thenar branch (extraligamentous). Anatomical variations involving the take-off of the median nerve motor branch (recurrent motor branch [RMB]) were first described by Lanz in 1977 [41] on 246 hands during a variety of surgical interventions. These anatomical variations can be categorized as follows (Fig. 2):

- Standard branching of the median nerve (extraligamentous);

- Thenar branch leaving the median nerve within the carpal tunnel (subligamentous);

- Transligamentous course of RMB;

- RMB leaving median nerve at its ulnar aspect;

- RMB crosses over the top of the transverse carpal ligament;

- Doubled RMB;

- High division of the median nerve with a persistent median artery (PMA) between the two parts; 


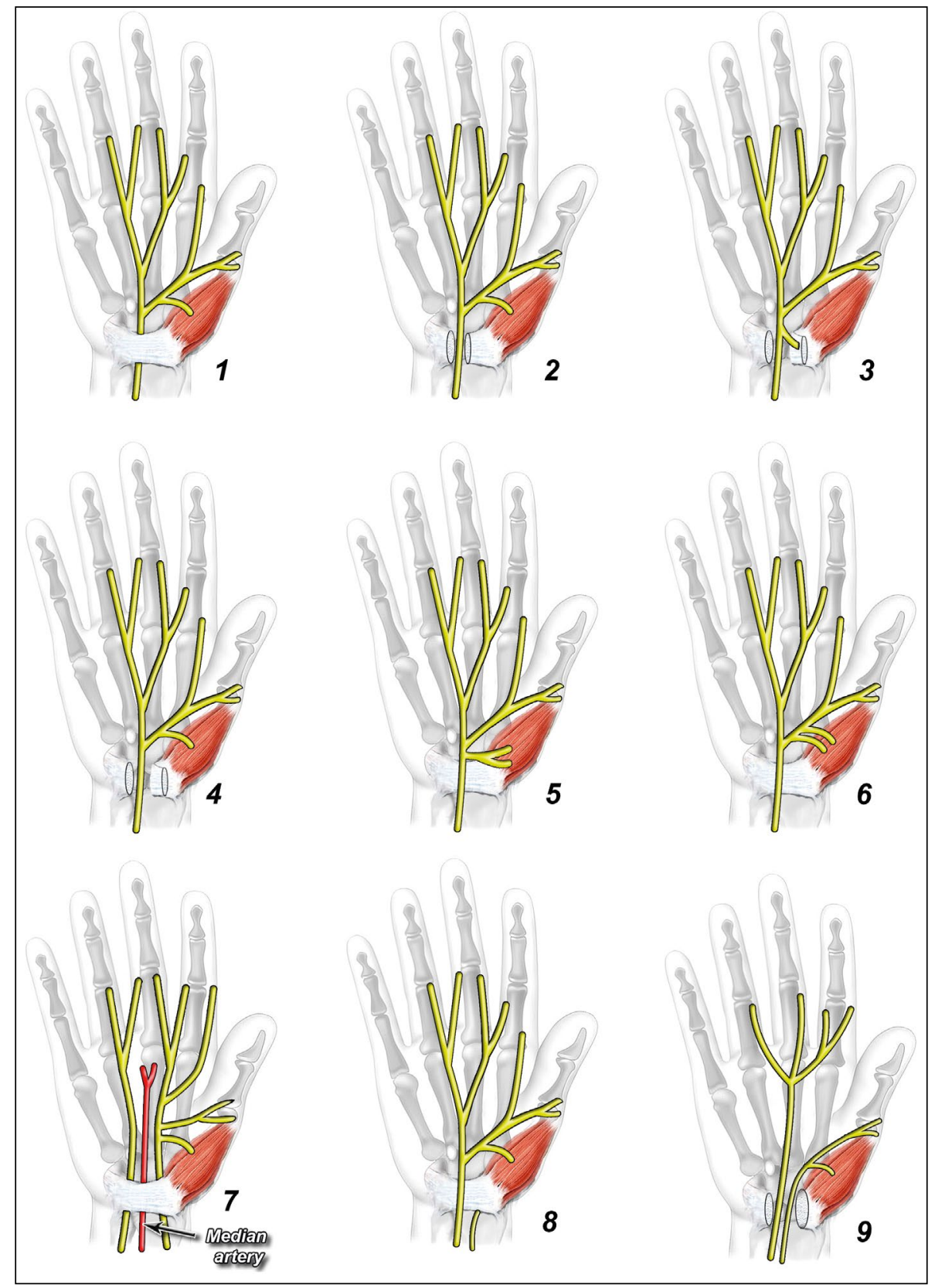

Figure 2. Anatomical variations of the median nerve in carpal tunnel. Redrawn from Lanz [41].

- High division of the median nerve with a thinner ulnar part;

- High division of the median nerve with a thicker ulnar part.

Poisel described three subtypes of RMB: $46 \%$ of cases were extraligamentous, $31 \%$ were subligamentous, and 23\% were transligamentous [61]. Dangerous varieties of the RMB occur very rarely in the population, but does not reduce from the fact that in each case special attention must be given [85]. Elsaftawy et al. [20] conclude that, at the minimally open carpal tunnel release procedure, the TCL should be released rather from the line of radial border of the $4^{\text {th }}$ finger to minimise the risk of injury to the recurrent motor branch of median nerve.

The presence of a PMA is another important consideration for plastic and orthopaedic surgeons who frequently perform open carpal tunnel release; mostly due to mechanical compression of the median nerve. Osiak et al. [54] identified PMA in 36 out of 1285 (2.8\%) operated hands. The observed PMAs were identified in $15(2.0 \%)$ cases out of 750 right upper limbs and in $21(3.9 \%)$ cases out of the 535 left upper limbs. Osiak et al. [54] along with Dickinson and 
Kleinert [17] unanimously recommend resection of a PMA if the perfusion of the hand remains normal after clamping the median artery and releasing the tourniquet.

\section{EPIDEMIOLOGY AND RISK FACTORS OF CTS}

Sir James Paget [59] first described compression of the median nerve at the wrist following a distal radius fracture in 1854. CTS is today the most common peripheral nerve entrapment syndrome worldwide $[53,57]$. It is defined as a compression of the median nerve at the level of the wrist joint associated with decreased function of the nerve at that level [80]. CTS is a largely idiopathic condition and affects $7-16 \%$ of the adult population [21]. It accounts for about $90 \%$ of all nerve compression syndromes. CTS is generally reported to be more common in females and increases with age with higher prevalence between 45 and 64 years of age. Occupational risk factors include forceful gripping, repetitive flexion and extension at the wrist and vibration exposure [43]. There is also a plethora of extrinsic and intrinsic factors that evoke secondary CTS. Of these factors; pregnancy, menopause, obesity, renal failure, hypothyroidism, the use of oral contraceptives, and congestive heart failure can contribute to CTS through increasing the volume of the synovial sheath within the tunnel [19]. CTS is among one of the most common musculoskeletal clinical presentations of mucopolysaccharidosis, reported in mucopolysaccharidosis types I, II, IV, and VI [60]. Direct fractures of the distal radius, posttraumatic arthritis and tumours, ganglion cysts or a persistent median artery can also alter the contour of the tunnel. Neuropathic factors, such as diabetes, alcoholism, vitamin toxicity or deficiency and exposure to toxins may elicit symptoms of CTS. This is due to the fact that these factors directly injure the median nerve without necessarily causing any spikes in the pressure within the carpal tunnel. The other causative factors include the morphological and mechanical changes (i.e. hypertrophy and stiffening) of the TCL which may lead to a significant reduction of carpal tunnel space and compliance. B-mode ultrasound imaging has proven to be a reliable method of measuring the thickness of the TCL at the distal portion of the carpal tunnel, noting increased ligament bowing or curvature, as well as pathological variations of TCL thickness $[50,67]$. Acoustic radiation force impulse imaging is a sonoelastographic another method of

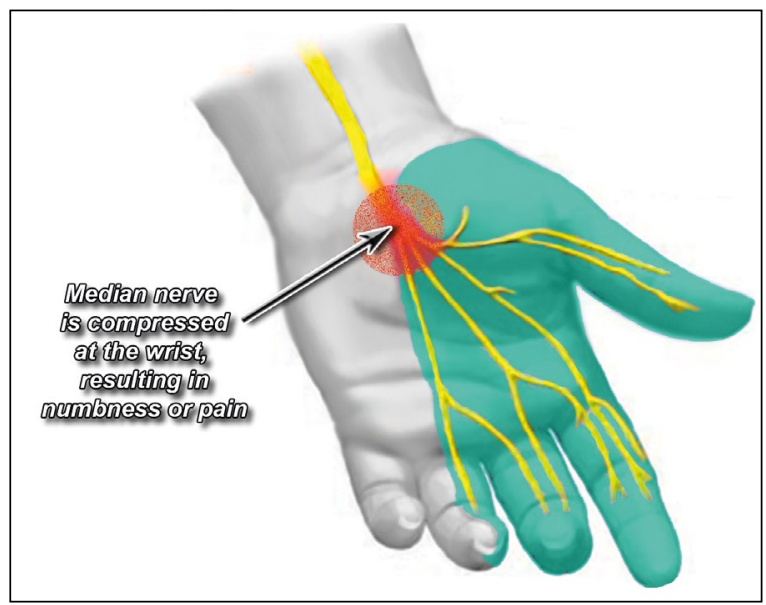

Figure 3. The area of sensory symptoms in the carpal tunnel syndrome.

objectively measuring changes in the TCL by mechanically exciting the tissues with a localized impulsive radiation force that results in measurable shear wave propagation, in terms of shear wave velocity (SWV). SWV has been correlated with tissue stiffness and is used to quantify the localized stiffness of the TCL as it rises in individuals with CTS [51].

Carpal tunnel syndrome is an early red-flag symptom of amyloidosis and is present in $10.2 \%$ of men aged 50 years and older and women aged 60 years old and older undergoing surgery for idiopathic CTS [18]. Carpal tunnel syndrome classically presents bilaterally, years before cardiac and multisystem involvement. Early diagnosis is paramount and consists of a simple biopsy of the tenosynovium, TCL, or fascia during carpal tunnel release surgery.

\section{PATHOPHYSIOLOGY}

Carpal tunnel syndrome occurs due to an increased interstitial pressure within the carpal tunnel ultimately resulting in compression and injury of the median nerve. The pathophysiology is not fully explained. However, it is hypothesized that due to the mechanical compression of the median nerve, ischaemia develops locally resulting in demyelination of both the small and large fibres of the median nerve; evoking characteristic symptoms (Fig. 3). Normal pressure in the carpal tunnel is recorded to vary between 2 and $10 \mathrm{mmHg}$. Repetitive motions of the wrist may result in significant fluctuations of the pressures within the carpal tunnel. Furthermore, extension at the wrist results in a ten-fold increase in the pressure, whilst wrist flexion is estimated to cause an eight-fold increase [79]. Subsequently, 
due to local compression, demyelination of the nerve develops and spreads to the internodal segment where the axons are left intact. With continuous compression, blood flow to the endoneurial capillary system is compromised, causing alterations in the blood-nerve barrier and the development of endoneurial oedema. Rapid symptom reversal is often noted following surgical decompression; supporting the theory that mechanical compression causes reversible, local ischaemia [56]. Sensory fibres are usually affected first before the motor fibres. This rise in pressure within the carpal tunnel results in a compartment syndrome that causes dramatic drop in epineurial perfusion and ischaemia. Moreover, this leads to swelling of the neural tissue and this further exacerbates the delays in nerve conduction already caused by the demyelination of the nerve fibres as discussed above. The possibility of damage reversal is dependent on the duration of ischaemia; a shorter duration of compression is readily reversible whereas longer periods increase the risk of irreversible neural damage [27]. The intraoperative view shows a thinned nerve in the region of compression and subsequent swelling of the nerve just proximal to the entrapment. It is hypothesized that this oedema is largely due to the build-up of axoplasm and chronic inflammatory fibrotic processes in the neural tissue. Inflammation often occurs due to increased release of prostaglandin E2 and other pro-angiogenic factors such as vascular endothelial growth factor [63]. The ultimate result is axonal degeneration and neuritis of the median nerve that causes slow nerve conduction and increased latency [19].

Zyluk [84] reviewed the role of genetic factors in CTS aetiology. Genetic predisposition to the development of CTS is based on some potential pathomechanisms that involve the synthesis and breakdown of collagen compounds as well as certain proteins which may protect against oxidative stress. Many different groups of genes (COL1A1, COL5A1 and COL11A1 genes) have been identified and are seen to play a role in the predisposition to CTS. These collagen-related genes govern the production of minor collagen compounds. Another family of genes was identified called the matrix metalloproteinases (MMPs). Subtypes of these MMP genes encode enzymes that function to remodel collagen whereas other subtypes are responsible for the production of glutathione S-transferase (GST) synthesis; a very well-established family of detoxification enzymes which work to defend against the toxic effects of oxidative stress. Therefore, lack of the products of these genes may result in some individuals being predisposed to the development of CTS due to their genetic makeup.

$\mathrm{Li}$ et al. [45] also revealed the critical roles of ECM proteins in the cellular stress response in the pathogenesis of CTS with identification of two causative mutations in cartilage oligomeric matrix protein (COMP). The genetic predisposition to CTS development is suspected with: early onset of CTS in young individuals, repeated disease occurrence in the same family as well as an increased incidence of CTS in relatives than in the general population. Genetic predisposition to the condition is also suspected where bilateral symptoms of CTS occur [62].

\section{SYMPTOMS}

The clinical presentation typically reveals irregularly occurring nocturnal paraesthesias that become more frequent when the patient is awake. Furthermore, there is loss of sensation in the thumb, index, middle, and radial side of the ring finger which coexists with weakness and ultimately atrophy of the thenar muscle as the disease progresses due to widespread axonal damage. The thenar area has normal sensation as the palmar cutaneous sensory branch innervates it, which does not pass through the carpal tunnel. This sequence of symptoms is quite typical and rather unique to CTS [57]. Patients' symptoms tend to worsen at night or during the hand's repetitive movements, especially those requiring prolonged wrist flexion [63].

Three stages of CTS can be distinguished based on the clinical symptoms. In the earliest stage, the patient's sleep is disturbed due to an overwhelming feeling of hand numbness and a swelling-like sensation although no swelling can be observed grossly. The patient may experience brachialgia paraesthetica nocturna; pain from the wrist radiating to the shoulder accompanied by tingling in the hand and digits. Oftentimes, patients observe that repetitive shaking of the hand may serve to alleviate the pain, the so called flick sign. In the second stage of clinical symptoms, patients may experience symptoms during the day and may also complain of frequent clumsiness when grasping an object with their hands. The third stage ensues when there is hypotrophy or atrophy of the thenar eminence. Sensory symptoms sometimes diminish in this third stage [82].

Another issue is the so called acute carpal tunnel syndrome (ACTS). It is well established that ACTS is a common sequela of trauma to the hand and/or wrist such as fractures of the distal radius. However, ACTS is 
also seen in many cases that do not involve trauma to this region. Patients generally lose two-point discrimination and may have elevated compartment pressure on measurement. Complete TCL release is indicated emergently in ACTS and any concomitant fractures should also be attended to appropriately [27].

\section{CLINICAL EXAMINATION}

In the diagnosis of CTS, the history (including type and characteristics of the symptoms, their distribution in the hand, and the presence or absence of other concurrent arm symptoms) is of utmost importance; however, it should be confirmed by electrophysiological testing and/or imaging evaluation, including magnetic resonance imaging and ultrasonography.

Furthermore, provocative tests are often employed in which different mechanical manoeuvres are used in attempt to reproduce the symptoms of CTS experienced by the patients. Among these, Tinel and Phalen tests are most commonly used in the clinical setting. Tinel sign is positive when repetitive tapping along the carpal tunnel produces symptoms in same distribution of the median nerve. In the Phalen manoeuvre, a patient is asked to flex their wrist to 90 degrees. A positive Phalen test is recorded when this manoeuvre produces symptoms in the median nerve distribution.

Sensitivity ranges from 0.28 to 0.73 for the Tinel test and from 0.46 to 0.80 for the Phalen test; specificity ranges from 0.44 to 0.95 and from 0.51 to 0.91 , respectively [16]. The scratch collapse test is a novel test originally developed by Susan Mackinnon, it is performed by applying a stimulus over an area of nerve compression while the patient is exerting bilateral external shoulder rotation [13, 35]. A positive test is noted if there is transient loss of muscle resistance resulting in the arm collapsing [29].

\section{BOSTON CARPAL TUNNEL SYNDROME QUESTIONNAIRE}

Validated patient-centred measures (e.g. the Boston Carpal Tunnel Syndrome Questionnaire [BCTQ]) are able to quantify symptoms and disability [58]. Level of disability is correlated with both clinical findings and nerve conduction findings. The BCTQ is widely used for assessment of patients with CTS and has been translated into many different languages [75].

\section{ELECTRODIAGNOSTIC TESTING}

Electrodiagnostic studies (EDX) include nerve conduction studies and electromyography. NCS confirm
CTS by detecting impaired median nerve conduction across the carpal tunnel, the so called median neuropathy at the wrist (MNW) with normal conduction elsewhere [55, 70]. Every patient with suspected CTS should undergo NCS before invasive treatment to confirm the diagnosis. The NCS are valid and reliable in confirming the clinical impression of CTS with a sensitivity of $>85 \%$ and a specificity of $95 \%$ [2]. EMG assesses pathologic changes in the muscles innervated by the median nerve, typically the abductor pollicis brevis muscle. In cases with longstanding and severe compression, there is evidence of denervation on EMG needle sampling of the abductor pollicis brevis muscle. The minimum requirements for the EDX evaluation of CTS outlined in the AANEM Practice Parameters and in Clinical Quality Measures published by the Carpal Tunnel Quality Group are testing of median sensory latency, testing of median distal motor latency, another sensory and motor nerve study in the same extremity, and, if these results are normal, followed by comparison short segment studies [33, 64, 83]. EDX study can augment the clinical diagnosis of CTS, assess its severity, determine its pathophysiology (demyelination vs. axon loss) and rule in/out coexistent conditions such as: cervical radiculopathy (especially C6-C7), coincidental ulnar nerve disease or polyneuropathy. It can also lead to identification of an alternative diagnosis: brachial plexopathy (especially of the upper trunk), neuropathy of the proximal median nerve (particularly at the level of the pronator teres muscle), thoracic outlet syndrome and a myriad of CNS disorders such as stroke or multiple sclerosis. Moreover, preoperative EDX ensures the acquisition of an objective baseline for comparison in cases of postoperative persistence or recurrence of symptoms [23, 24].

\section{ULTRASOUND}

The use of ultrasound has been implicated in the diagnosis of CTS because thickening of the median nerve, flattening of the nerve within the tunnel and bowing of the flexor retinaculum are all features diagnostic of CTS. Ultrasound may reveal an increased cross-sectional area (CSA) of the nerve, measured at the level of the pisiform, just before it is flattened at the site of compression. A meta-analysis found that a cross-sectional area of $9 \mathrm{~mm}^{2}$ or more is $87.3 \%$ sensitive and $83.3 \%$ specific for CTS [73]. CSA of the median nerve is a highly reproducible parameter and has demonstrated acceptable reliability indicative of carpal tunnel syndrome. According to Fowler et al. [24] this technique has sen- 
sitivity and specificity $77.6 \%$ and $86.8 \%$ respectively regarding CTS diagnosis. Thus, ultrasound adds value to EDX diagnosis and can be used as a complementary diagnostic modality that also allows screening for structural abnormalities at the wrist.

\section{MAGNETIC RESONANCE IMAGING}

Magnetic resonance reliably images the flexor retinaculum and carpal bones and thus defines the borders of the carpal tunnel. The median nerve is seen as an ovoid structure of moderate signal intensity and is easily distinguished from the flexor tendons of the hands running in the carpal tunnel. Magnetic resonance imaging serves as an extremely useful tool for evaluation of primary nerve pathologies and for the assessment of space-occupying lesions leading to its compression such as haemangioma, ganglion or bony deformity that may alter the range of surgical intervention [39].

\section{NON-SURGICAL TREATMENT}

Initial treatment for mild and moderate CTS is nonsurgical and includes wrist splinting, local corticosteroid injections, and oral medications. Non-surgical management should be also considered if symptoms can reverse spontaneously (e.g. during pregnancy). The rationale for wrist splinting is based on observations that CTS symptoms improve with rest and aggravate with activity [78]. The use of a rigid neutral splint immobilising the wrist, usually during night-time, for 6 weeks results in better clinical improvements in patients with untreated mild and mild to moderate CTS. There is no additional benefit in extending splinting for additional 6 weeks [7].

Local corticosteroid injections into carpal tunnel decrease pressure within the tunnel by reducing inflammation and oedema of the tenosynovium passing through it [56]. This management for severe CTS provides symptomatic advantage at 1 month as compared to placebo; however, in mild and moderate cases the advantage beyond 1 month remains uncertain [5]. The main adverse effect of local corticosteroids injection is suppression of collagen and proetoglycan synthesis in tenocytes evoking a decrease in the mechanical strength of the tendon and its further degeneration. The use of oral steroids, i.e. prednisone, has shown some benefit only in the short-term treatment of CTS.

Non-steroidal anti-inflammatory drugs (NSAIDs) and diuretics have proved no clear benefit and are not recommended in the treatment of CTS [56].
The conservative approach may be effective during the initial phase of the disease and delay the surgical intervention [11].

\section{SURGICAL TREATMENT}

Strong scientific evidence supports the operative treatment of CTS $[4,26,31,34,46,47]$. Simple decompression of the median nerve by longitudinal division of TCL is the treatment of choice. This can be done either with an open approach or endoscopically. In terms of long-term functional outcome, there is no significant difference between open and endoscopic release $[12,42,52,66,72]$.

Open carpal tunnel release (OCTR) is generally accepted method, and reported high success rates with minimal complications, although in the worst case scenario, some wound related symptoms may persist for 2 years postoperatively [36]. This surgery is indicated and feasible for CTS with any type of pathology, such as CTS due to any space occupying lesion, deformity or even in revision surgeries. Endoscopic release is more expensive and is associated with higher rates of transient nerve damage [68]. Appropriate patient selection is important for successful outcomes. Patients with known anatomic anomalies, fracture history, previous CTS surgery, or inflammatory tenosynovitis are probably best served with an open or mini-open approach (limited open release with direct vision and tunnelling technique) which may or may not be followed by a longitudinal epineurotomy.

\section{AUTHORS' PREFERRED SURGICAL TECHNIQUE}

Open carpal tunnel release remains the authors' preferred surgical method for treatment. Patient is positioned supine with the operative arm extended onto a hand table. A nonsterile tourniquet on the upper arm is applied to those undergoing regional anaesthesia, whereas no tourniquet is applied in the wide-awake local anaesthesia group. The patient undergoes preparation and draping. A standard open (extensile) Tanzer's skin incision is performed $2-3 \mathrm{~mm}$ ulnar to the thenar crease in line with the third web space from just distal to Kaplan's oblique line (a line drawn from the apex of the interdigital fold between the thumb and index finger to the ulnar side of the hand, running parallel to the proximal palmar crease) to the distal wrist crease (Fig. 4). The incision is then extended $0.5 \mathrm{~cm}$ proximal to the ulnar side 


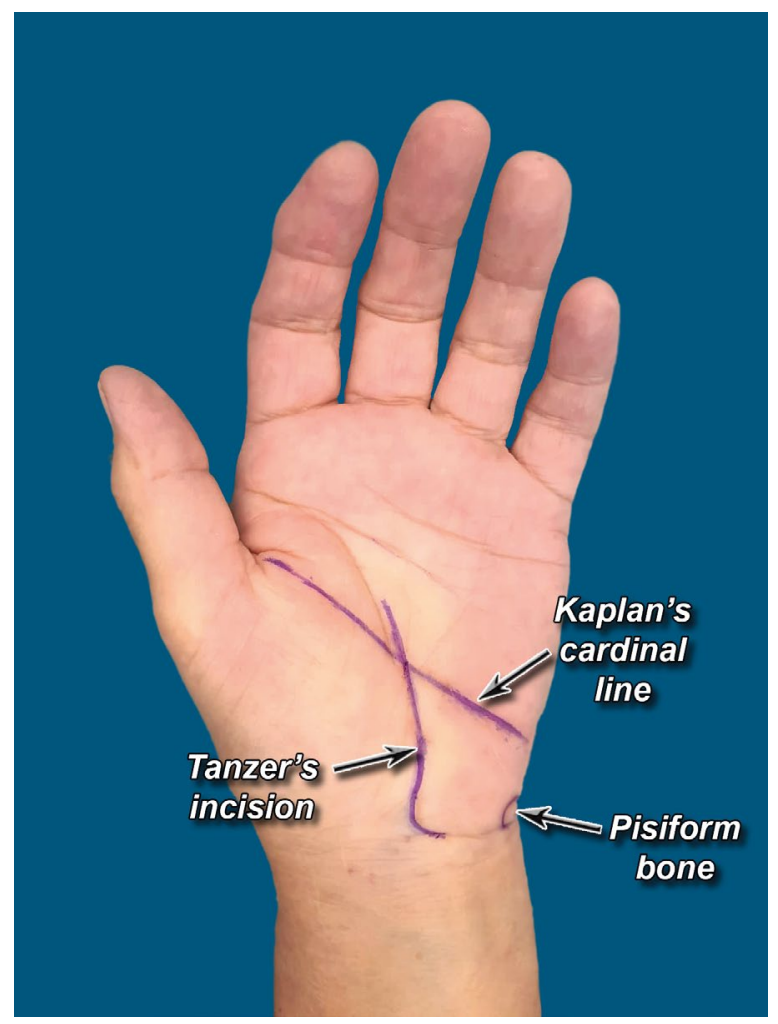

Figure 4. Tanzer's skin incision for open carpal tunnel release, crossing Kaplan's cardinal line, which runs parallel with the middle crease of the hand.

at a $45^{\circ}$ angle. Thus, PCBMN can be protected but if severed care should be taken that its proximal end does not become incorporated into the scar, since this may result in bothersome postoperative dysthesias. The superficial palmar fascia is cut in line with the skin incision. The transverse carpal ligament is identified and released longitudinally until complete decompression of the median nerve is confirmed (Fig. 5). Our experience confirms the necessity for approaching the median nerve from the ulnar side when opening the carpal tunnel in order to avoid lacerations of variant branches. Following section of the ligament, scissors may be used to spread beneath the subcutaneous tissues, and the forearm fascia is split proximally for a distance of about one inch. The nerve is usually inflamed and it may be constricted beneath the mid-portion of the ligament (Fig. 6). Surgical release of the tunnel reduces pressure, allows for restoration of the intraneuronal blood flow and physiological function. The open-field approach allows for manipulations that could additionally improve the outcomes. Long-lasting nerve compression may result in fibrotic changes generating further mechanical pressure and narrowing of the nerve. In

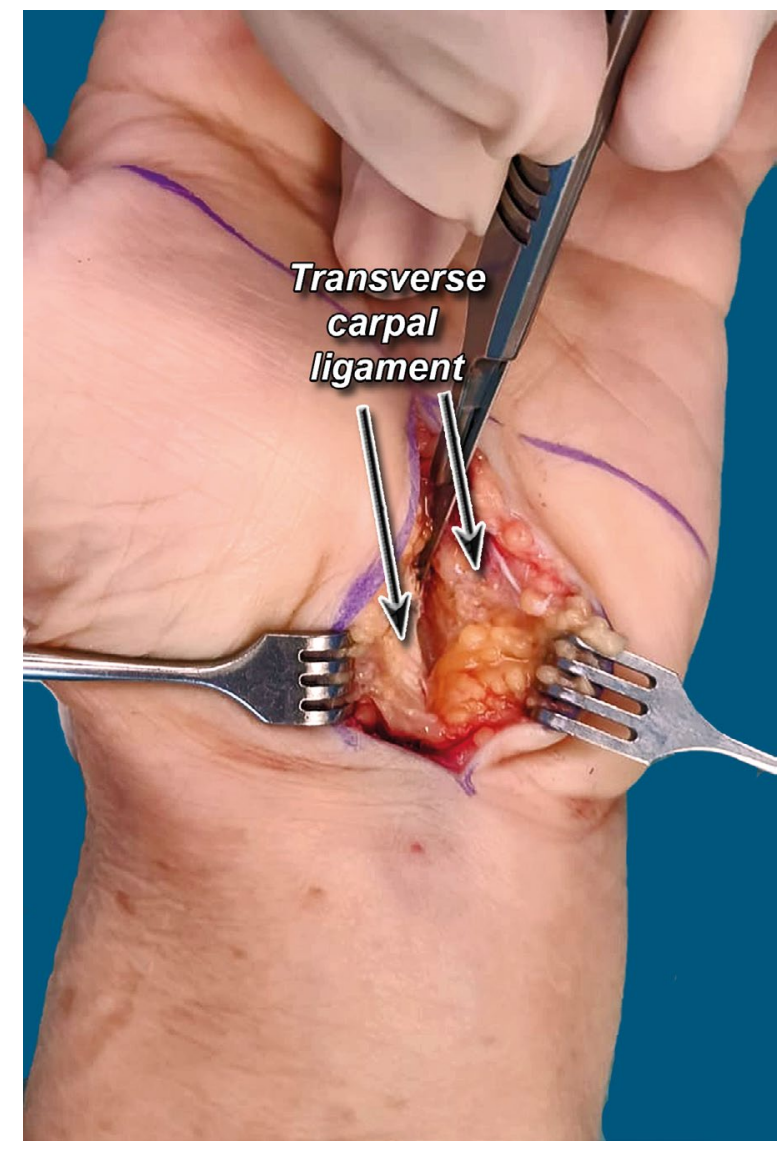

Figure 5. Longitudinal division of transverse carpal ligament.

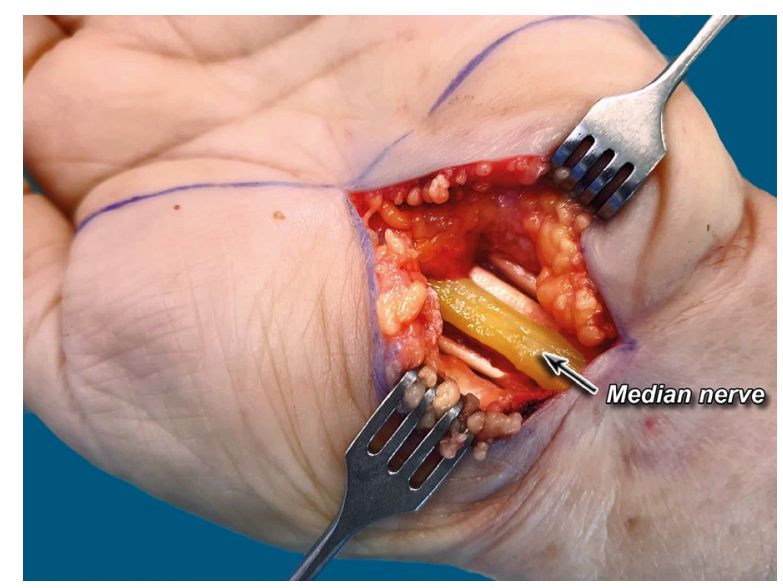

Figure 6. Median nerve exposed in the carpal tunnel after transverse carpal ligament division.

such cases, longitudinal epineurotomy of the nerve as described by Foulkes et al. [22] and Leinberry et al. [44] has been suggested as an option that could convey a greater pressure release, a more prominent nerve volume recovery and better outcomes [15]. If a thickened epineurium is present, it should be incised. Usually the flexor synovialis is inflamed, oedematous 
and of greater bulk than the usual filmy synovial covering. As much as possible of this abnormal synovium should be removed. The floor of the canal should be completely inspected since other lesions such as carpal ganglia may encroach upon the contents of the canal. Before closure the tourniquet is released, and when this is done it is interesting to note the segmental hyperaemia which is present in the portion of the median nerve lying beneath the ligament. The drain is placed and the skin incisions are closed with 4-0 nylon horizontal mattress sutures followed by application of soft sterile compression dressing. The cast immobilisation with wrist in dorsiflexion (5 to 10 degrees) is applied for 10 days. Finger and thumb motion is emphasized to the patient in the postoperative period. After removal of the immobilisation and sutures, all patients undergo the same rehabilitation protocol (cryotherapy, exercises of hand mobility, grip strength and limb circulation).

\section{COMPLICATIONS}

Carpal tunnel decompression appears to be a safe operation in most patients, with an overall serious complication rate (requiring admission to hospital or further surgery) of less than $0.1 \%$ [40]. Serious complications include surgical site infection or dehiscence, or neurovascular or tendon injury. Fortunately, injury to major neurovascular structures during carpal tunnel release is exceedingly low. Permanent nerve injury more commonly occurs to the branches of the median nerve, including the PCBMN $(0.03 \%)$, the RMB $(0.01 \%)$, or the common digital nerves $(0.12 \%)$, compared with injury to the median nerve itself $(0.06 \%)$ [65]. Injuries to adjacent structures, including flexor tendons $(0.1 \%)$, superficial palmar arch $(0.1 \%)$, and the ulnar nerve $(0.03 \%)$ have been also described $[9,69]$. Endoscopic techniques may result in a slightly higher rate of subsequent nerve repair $(0.13-0.3 \%)$ vs. open techniques $(0.10-0.2 \%)$ [74]. Frequent postoperative problems include persistent weakness, pillar pain (deep-seated ache or pain over the thenar or hypothenar region, or both), and scar tenderness, which contribute greatly to patient dissatisfaction and time lost from work [10]. Preserving PCBMN during open surgery may overcome these complications in some patients [1]. Evaluation of pillar pain can be evoked with the "table test" in which the patient stands approximately $40 \mathrm{~cm}$ from the foot of the table, then with elbows straight, leans over and places both hands on the edge of the exam table.
Pain elicited with this test is considered pillar pain. Burning discomfort, pillar pain, scar tenderness, and even Tinel's sign can be expected in a small number of patients after OCTR surgery, even after follow-up of almost 2 years. Although rarely causing dissatisfaction, it is important to inform the patient regarding the potential complications related to OCTR.

The failure rate of surgical treatment for CTS ranges from $3 \%$ to $20 \%$, regardless the surgical technique used. Wulle defined recurrent CTS [81] as the reappearance, after a symptom-free period of at least 3 months, of the initial symptoms after surgical release. There are several contributing factors such as secondary causes, scar adhesions and perineural fibrosis, along with incomplete opening of the TCL anterior to the carpus, especially in its distal portion. Surgical revision may be required for persistent, recurrent, or new symptoms [77]. In those with persistent or recurrent symptoms, scarring of the median nerve to the flexor retinaculum and incomplete release were the most common findings. In those with new symptoms, nerve injuries were a common finding [76]. The vascularised coverage for the median nerve is often recommended. Coverage methods include Strickland's hypothenar fat flap, an abductor digiti minimi flap or a radial artery perforator fascial flap [6, 14, 49].

Krzesniak et al. [37] proposed the use of autologous fat transfer during secondary carpal tunnel revision. The benefits of fat grafting have been previously observed with other applications for skin quality improvement, tissue regeneration and scarring inhibition [37]. Fat tissue deposited in the carpal tunnel directly around the nerve forms a pad for regeneration, and the multipotent stem cells from the fat may influence and even stimulate nerve fibre regeneration. A small amount of fat can be easily harvested from the abdomen or thighs and transferred into carpal tunnel tissues. The procedure is minimally invasive and may easily replace other proposed methods. Simultaneous nerve release with adipose-derived stromal/stem cells support is also a promising method in patients who need secondary nerve release after nerve reconstruction. This method can constitute an alternative procedure in patients experiencing recovery failure and allow improvement in cases of limited nerve regeneration [38].

\section{CONCLUSIONS}

Carpal tunnel syndrome remains one of the most well-known and frequent forms of median nerve 
entrapment, and accounts for $90 \%$ of all entrapment neuropathies. Strenuous use of the hand is a risk factor. Comorbidities associated with the development of CTS include diabetes and obesity. Initial management is non-operative, with the evidence to support the efficacy of neutral wrist splints. Strong evidence supports operative treatment, regardless of technique, as superior to non-operative management. Complications are infrequent and most are minor and transient.

\section{Conflict of interest: None declared}

\section{REFERENCES}

1. Ahcan U, Arnez ZM, Bajrović F, et al. Surgical technique to reduce scar discomfort after carpal tunnel surgery. J Hand Surg Am. 2002; 27(5): 821-827, doi: 10.1053/ jhsu.2002.35083, indexed in Pubmed: 12239671.

2. Alanazy MH. Clinical and electrophysiological evaluation of carpal tunnel syndrome: approach and pitfalls. Neurosciences (Riyadh). 2017; 22(3): 169-180, doi: 10.17712/ nsj.2017.3.20160638, indexed in Pubmed: 28678210.

3. Amadio PC. The first carpal tunnel release? J Hand Surg Br. 1995; 20(1): 40-41, doi: 10.1016/s0266-7681(05)80013-0, indexed in Pubmed: 7759932.

4. Andreu JL, Ly-Pen D, Millán I, et al. Local injection versus surgery in carpal tunnel syndrome: neurophysiologic outcomes of a randomized clinical trial. Clin Neurophysiol. 2014; 125(7): 1479-1484, doi: 10.1016/j. clinph.2013.11.010, indexed in Pubmed: 24321619.

5. Ashworth NL, Bland JDP, Marshall S, et al. Local corticosteroid injection for carpal tunnel syndrome. Cochrane Database Syst Rev. 2000; 48(4): CD001554-126, doi: 10.1002/14651858. CD001554, indexed in Pubmed: 11034724.

6. Athlani L, Haloua JP. Strickland's hypothenar fat pad flap for revision surgery in carpal tunnel syndrome: Prospective study of 34 cases. Hand Surg Rehabil. 2017; 36(3): 202-207, doi: 10.1016/j.hansur.2016.12.009, indexed in Pubmed: 28465201.

7. Atroshi I, Tadjerbashi K, McCabe SJ, et al. Treatment of carpal tunnel syndrome with wrist splinting: study protocol for a randomized placebo-controlled trial. Trials. 2019; 20(1): 531, doi: 10.1186/s13063-019-3635-6, indexed in Pubmed: 31455398.

8. Bland JDP. Carpal tunnel syndrome. BMJ. 2007; 335(7615): 343-346, doi: 10.1136/bmj.39282.623553.AD, indexed in Pubmed: 17703044.

9. Boeckstyns ME, Sørensen Al. Does endoscopic carpal tunnel release have a higher rate of complications than open carpal tunnel release? An analysis of published series. J Hand Surg Br. 1999; 24(1): 9-15, doi: 10.1016/ s0266-7681(99)90009-8, indexed in Pubmed: 10190596.

10. Boya H, Özcan Ö, Özteki N HH. Long-term complications of open carpal tunnel release. Muscle Nerve. 2008; 38(5): 1443-1446, doi: 10.1002/mus.21068, indexed in Pubmed: 18949783.

11. Chandra PS, Singh PK, Goyal V, et al. Early versus delayed endoscopic surgery for carpal tunnel syndrome: prospective randomized study. World Neurosurg. 2013; 79(5-6): 767-772, doi: 10.1016/j.wneu.2012.08.008, indexed in Pubmed: 23022645.
12. Chen L, Duan X, Huang $X$, et al. Effectiveness and safety of endoscopic versus open carpal tunnel decompression. Arch Orthop Trauma Surg. 2014; 134(4): 585-593, doi: 10.1007/s00402-013-1898-z, indexed in Pubmed: 24414237.

13. Cheng CJ, Mackinnon-Patterson B, Beck JL, et al. Scratch collapse test for evaluation of carpal and cubital tunnel syndrome. J Hand Surg Am. 2008; 33(9): 1518-1524, doi: 10.1016/j.jhsa.2008.05.022, indexed in Pubmed: 18984333.

14. Cheung K, Klausmeyer MA, Jupiter JB. Abductor digiti minimi flap for vascularized coverage in the surgical management of complex regional pain syndrome following carpal tunnel release. Hand (N Y). 2017; 12(6): 546-550, doi: 10.1177/1558944716681977, indexed in Pubmed: 29091494.

15. Crnković T, Bilić R, Trkulja V, et al. The effect of epineurotomy on the median nerve volume after the carpal tunnel release: a prospective randomised double-blind controlled trial. Int Orthop. 2012; 36(9): 1885-1892, doi: 10.1007/ s00264-012-1565-y, indexed in Pubmed: 22588692.

16. Dengler J, Stephens JD, Bamberger HB, et al. Mimickers of carpal tunnel syndrome. JBJS Rev. 2020; 8(2): e0087, doi: 10.2106/JBJS.RVW.19.00087, indexed in Pubmed: 32224629.

17. Dickinson JC, Kleinert JM. Acute carpal-tunnel syndrome caused by a calcified median artery. A case report. J Bone Joint Surg Am. 1991; 73(4): 610-611, indexed in Pubmed: 2013602.

18. Donnelly JP, Hanna M, Sperry BW, et al. Carpal tunnel syndrome: a potential early, red-flag sign of amyloidosis. J Hand Surg Am. 2019; 44(10): 868-876, doi: 10.1016/j. jhsa.2019.06.016, indexed in Pubmed: 31400950.

19. Duncan S, Bhate O, Mustaly H. Pathophysiology of carpal tunnel syndrome. Carpal Tunnel Syndrome and Related Median Neuropathies. 2017: 13-29, doi: 10.1007/9783-319-57010-5_3.

20. Elsaftawy A, Gworys B, Jabłecki J, et al. "Dangerous" anatomic varieties of recurrent motor branch of median nerve. Pol Przegl Chir. 2013; 85(8): 419-423, doi: 10.2478/ pjs-2013-0064, indexed in Pubmed: 24009051.

21. Ferry S, Pritchard T, Keenan J, et al. Estimating the prevalence of delayed median nerve conduction in the general population. Br J Rheumatol. 1998; 37(6): 630-635, doi: 10.1093/rheumatology/37.6.630, indexed in Pubmed: 9667616.

22. Foulkes GD, Atkinson RE, Beuchel $C$, et al. Outcome following epineurotomy in carpal tunnel syndrome: a prospective, randomized clinical trial. J Hand Surg Am. 1994; 19(4): 539-547, doi: 10.1016/0363-5023(94)90253-4, indexed in Pubmed: 7963304.

23. Fowler JR. Nerve conduction studies for carpal tunnel syndrome: gold standard or unnecessary evil? Orthopedics. 2017; 40(3): 141-142, doi: 10.3928/01477447-20170419-01, indexed in Pubmed: 28514489.

24. Fowler JR, Gaughan JP, Ilyas AM. The sensitivity and specificity of ultrasound for the diagnosis of carpal tunnel syndrome: a meta-analysis. Clin Orthop Relat Res. 2011; 469(4): 1089-1094, doi: 10.1007/s11999-010-1637-5, indexed in Pubmed: 20963527.

25. Franklin GM, Friedman AS. Work-Related carpal tunnel syndrome: diagnosis and treatment guideline. Phys Med Rehabil Clin N Am. 2015; 26(3): 523-537, doi: 10.1016/j. pmr.2015.04.003, indexed in Pubmed: 26231963. 
26. Gerritsen AAM, de Vet HCW, Scholten RJ, et al. Splinting vs surgery in the treatment of carpal tunnel syndrome: a randomized controlled trial. JAMA. 2002; 288(10): 1245-1251, doi: 10.1001/jama.288.10.1245, indexed in Pubmed: 12215131.

27. Gillig JD, White SD, Rachel JN. Acute carpal tunnel syndrome: a review of current literature. Orthop Clin North Am. 2016; 47(3): 599-607, doi: 10.1016/j. ocl.2016.03.005, indexed in Pubmed: 27241382.

28. Goldberg G, Zeckser JM, Mummaneni R, et al. Electrosonodiagnosis in carpal tunnel syndrome: a proposed diagnostic algorithm based on an analytic literature review. PM R. 2016; 8(5): 463-474, doi: 10.1016/j.pmrj.2015.11.016, indexed in Pubmed: 26804668.

29. Huynh MNQ, Karir A, Bennett A. Scratch collapse test for carpal tunnel syndrome: a systematic review and meta-analysis. Plast Reconstr Surg Glob Open. 2018; 6(9): e1933, doi: 10.1097/GOX.0000000000001933, indexed in Pubmed: 30349795

30. Iskra T, Mizia E, Musial A, et al. Carpal tunnel syndrome: anatomical and clinical correlations. Folia Med Cracov. 2013; 53(2): 5-13, indexed in Pubmed: 24858452.

31. Ismatullah I. Local steroid injection or carpal tunnel release for carpal tunnel syndrome: Which is more effective? J Postgrad Med Inst. 2013; 27(2): 194-199.

32. Jablecki CK, Andary MT, Floeter MK, et al. Practice parameter: Electrodiagnostic studies in carpal tunnel syndrome. Report of the American Association of Electrodiagnostic Medicine, American Academy of Neurology, and the American Academy of Physical Medicine and Rehabilitation. Neurology. 2002; 58(11): 1589-1592, doi: 10.1212/ wnl.58.11.1589, indexed in Pubmed: 12058083.

33. Jablecki CK, Andary MT, Floeter MK, et al. Practice parameter for electrodiagnostic studies in carpal tunnel syndrome: Summary statement. Muscle Nerve. 2002; 25(6): 918-922, doi: 10.1002/mus.10185.

34. Jarvik JG, Comstock BA, Kliot M, et al. Surgery versus non-surgical therapy for carpal tunnel syndrome: a randomised parallel-group trial. Lancet. 2009; 374(9695): 1074-1081, doi: 10.1016/S0140-6736(09)61517-8, indexed in Pubmed: 19782873

35. Kahn LC, Yee A, Mackinnon SE. Important details in performing and interpreting the scratch collapse test. Plast Reconstr Surg. 2018; 141(2): 399-407, doi: 10.1097/ PRS.0000000000004082, indexed in Pubmed: 29036022.

36. Kim PT, Lee HJ, Kim TG, et al. Current approaches for carpal tunnel syndrome. Clin Orthop Surg. 2014; 6(3): 253-257, doi: 10.4055/cios.2014.6.3.253, indexed in Pubmed: 25177448.

37. Krześniak NE, Noszczyk BH. Autologous fat transfer in secondary carpal tunnel release. Plast Reconstr Surg Glob Open. 2015; 3(5): e401, doi: 10.1097/ GOX.0000000000000374, indexed in Pubmed: 26090291.

38. Krzesniak NE, Sarnowska A, Figiel-Dabrowska A, et al. Secondary release of the peripheral nerve with autologous fat derivates benefits for functional and sensory recovery. Neural Regen Res. 2021; 16(5): 856-864, doi: 10.4103/16735374.297081, indexed in Pubmed: 33229720.

39. Kumari A, Singh S, Garg A, et al. Tingling hand: magnetic resonance imaging of median nerve pathologies within the carpal tunnel. Pol J Radiol. 2019; 84: e484-e490, doi: 10.5114/ pjr.2019.90354, indexed in Pubmed: 32082444.

40. Lane JCE, Craig RS, Rees JL, et al. Serious postoperative complications and reoperation after carpal tunnel decom- pression surgery in England: a nationwide cohort analysis. Lancet Rheumatol. 2021; 3(1): e49-e57, doi: 10.1016/ S2665-9913(20)30238-1, indexed in Pubmed: 33381769.

41. Lanz U. Anatomical variations of the median nerve in the carpal tunnel. J Hand Surg Am. 1977; 2(1): 44-53, doi: 10.1016/s0363-5023(77)80009-9, indexed in Pubmed: 839054.

42. Larsen MB, Sørensen Al, Crone KL, et al. Carpal tunnel release: a randomized comparison of three surgical methods. J Hand Surg Eur Vol. 2013; 38(6): 646-650, doi: 10.1177/1753193412475247, indexed in Pubmed: 23340761.

43. Lawson IJ. Is carpal tunnel syndrome caused by work with vibrating tools? Occup Med (Lond). 2020; 70(1): 8-10, doi: 10.1093/occmed/kqz142, indexed in Pubmed: 32161963

44. Leinberry CF, Hammond NL, Siegfried JW. The role of epineurotomy in the operative treatment of carpal tunnel syndrome. J Bone Joint Surg Am. 1997; 79(4): 555-557, doi: 10.2106/00004623-199704000-00011, indexed in Pubmed: 9111400.

45. Li C, Wang Ni, Schäffer AA, et al. Mutations in COMP cause familial carpal tunnel syndrome. Nat Commun. 2020; 11(1): 3642, doi: 10.1038/s41467-020-17378-z, indexed in Pubmed: 32686688.

46. Ly-Pen $\mathrm{D}$, Andréu JL, Millán I, et al. [Treatment of carpal tunnel syndrome]. Med Clin (Barc). 2005; 125(15): 585-589, doi: 10.1157/13080654, indexed in Pubmed: 16277952.

47. Ly-Pen D, Andréu JL, Millán I, et al. Comparison of surgical decompression and local steroid injection in the treatment of carpal tunnel syndrome: 2-year clinical results from a randomized trial. Rheumatology (Oxford). 2012; 51(8): 1447-1454, doi: 10.1093/rheumatology/kes053, indexed in Pubmed: 22467087.

48. MacDermid JC, Wessel J. Clinical diagnosis of carpal tunnel syndrome: a systematic review. J Hand Ther. 2004; 17(2): 309-319, doi: 10.1197/j.jht.2004.02.015, indexed in Pubmed: 15162113.

49. Mahmoud M, El Shafie S, Coppola EE, et al. Perforator-based radial forearm fascial flap for management of recurrent carpal tunnel syndrome. J Hand Surg Am. 2013; 38(11): 2151-2158, doi: 10.1016/j.jhsa.2013.06.034, indexed in Pubmed: 24206978.

50. Marquardt TL, Evans PJ, Seitz WH, et al. Carpal arch and median nerve changes during radioulnar wrist compression in carpal tunnel syndrome patients. J Orthop Res. 2016; 34(7): 1234-1240, doi: 10.1002/jor.23126, indexed in Pubmed: 26662276.

51. Marquardt TL, Gabra JN, Evans PJ, et al. Thickness and stiffness adaptations of the transverse carpal ligament associated with carpal tunnel syndrome. J Musculoskelet Res. 2016; 19(4), doi: 10.1142/S0218957716500196, indexed in Pubmed: 28824216.

52. Michelotti B, Romanowsky D, Hauck RM. Prospective, randomized evaluation of endoscopic versus open carpal tunnel release in bilateral carpal tunnel syndrome: an interim analysis. Ann Plast Surg. 2014; 73 Suppl 2: S157-S160, doi: 10.1097/SAP.0000000000000203, indexed in Pubmed: 25046667.

53. Olney RK. Carpal tunnel syndrome: complex issues with a "simple" condition. Neurology. 2001; 56(11): 1431-1432, doi: 10.1212/wnl.56.11.1431, indexed in Pubmed: 11402097. 
54. Osiak K, Elnazir P, Mazurek A, et al. Prevalence of the persistent median artery in patients undergoing surgical open carpal tunnel release: A case series. Transl Res Anat. 2021; 23, doi: 10.1016/j.tria.2021.100113.

55. Osiak K, Mazurek A, Pękala P, et al. Electrodiagnostic studies in the surgical treatment of carpal tunnel syndrome: a systematic review. J Clin Med. 2021; 10(12), doi: 10.3390/ jcm10122691, indexed in Pubmed: 34207345.

56. Ostergaard PJ, Meyer MA, Earp BE. Non-operative treatment of carpal tunnel syndrome. Curr Rev Musculoskelet Med. 2020; 13(2): 141-147, doi: 10.1007/s12178-02009616-0, indexed in Pubmed: 32124335.

57. Padua L, Coraci D, Erra C, et al. Carpal tunnel syndrome: clinical features, diagnosis, and management. Lancet Neurol. 2016; 15(12): 1273-1284, doi: 10.1016/S14744422(16)30231-9, indexed in Pubmed: 27751557.

58. Padua L, Padua R, Lo Monaco M, et al. Multiperspective assessment of carpal tunnel syndrome: a multicenter study. Italian CTS Study Group. Neurology. 1999; 53(8): 1654-1659, doi: 10.1212/wnl.53.8.1654, indexed in Pubmed: 10563608.

59. Paget J. Lectures on surgical pathology. 2nd Americ. Lindsay \& Blakiston, Philadelphia 1860.

60. Patel P, Antoniou G, Clark D, et al. Screening for carpal tunnel syndrome in patients with mucopolysaccharidosis. J Child Neurol. 2020; 35(6): 410-417, doi: 10.1177/0883073820904481, indexed in Pubmed: 32157938.

61. Poisel S. Ursprung und Verlauf des Ramusmuscularis des N. digitalis palmaris communis I (N. medianus). Chir Prax. 1974; 18: 471-474.

62. Puchalski P, Szlosser Z, Żyluk A. Familial occurrence of carpal tunnel syndrome. Neurol Neurochir Pol. 2019; 53(1): 43-46, doi: 10.5603/PJNNS.a2019.0004, indexed in Pubmed: 30620043.

63. Rosario NB, De Jesus O. Electrodiagnostic Evaluation Of Carpal Tunnel Syndrome. StatPearls [Internet]. Treasure Island (FL): StatPearls Publishing. 2021.

64. Sandin KJ, Asch SM, Jablecki CK, et al. Clinical quality measures for electrodiagnosis in suspected carpal tunnel syndrome. Muscle Nerve. 2010; 41(4): 444-452, doi: 10.1002/mus.21617, indexed in Pubmed: 20336661.

65. Santosa KB, Chung KC, Waljee JF. Complications of compressive neuropathy: prevention and management strategies. Hand Clin. 2015; 31(2): 139-149, doi: 10.1016/j. hcl.2015.01.012, indexed in Pubmed: 25934192.

66. Sayegh ET, Strauch RJ. Open versus endoscopic carpal tunnel release: a meta-analysis of randomized controlled trials. Clin Orthop Relat Res. 2015; 473(3): 1120-1132, doi: 10.1007/ s11999-014-3835-z, indexed in Pubmed: 25135849.

67. Shen ZL, Li ZM. Ultrasound assessment of transverse carpal ligament thickness: a validity and reliability study. Ultrasound Med Biol. 2012; 38(6): 982-988, doi: 10.1016/j.ultrasmedbio.2012.02.021, indexed in Pubmed: 22502882.

68. Shin EK. Endoscopic versus open carpal tunnel release. Curr Rev Musculoskelet Med. 2019; 12(4): 509-514, doi: 10.1007/s12178-019-09584-0, indexed in Pubmed: 31773481.

69. Shinya K, Lanzetta M, Conolly WB. Risk and complications in endoscopic carpal tunnel release. J Hand Surg Br. 1995; 20(2): 222-227, doi: 10.1016/s0266-7681(05)80056-7, indexed in Pubmed: 7797976.

70. Sonoo M, Menkes DL, Bland JDP, et al. Nerve conduction studies and EMG in carpal tunnel syndrome: Do they add value? Clin Neurophysiol Pract. 2018; 3:
78-88, doi: 10.1016/j.cnp.2018.02.005, indexed in Pubmed: 30215013.

71. Spinner RJ, Dellon AL. Emanuel B. Kaplan, M.D. (1894-1980): A Legendary Anatomist and Hand Surgeon. Clin Anat. 2018; 31(8): 1104-1108, doi: 10.1002/ca.23245, indexed in Pubmed: 30069977.

72. Steiner CA, Maggard-Gibbons M, Raetzman SO, et al. Extended Follow-up of a Randomized Clinical Trial of Open vs Endoscopic Release Surgery for Carpal Tunnel Syndrome. JAMA. 2015; 314(13): 1399-1401, doi: 10.1001_ jama.2015.12208, indexed in Pubmed: 26441187.

73. Tai TW, Wu CY, Su FC, et al. Ultrasonography for diagnosing carpal tunnel syndrome: a meta-analysis of diagnostic test accuracy. Ultrasound Med Biol. 2012; 38(7): 1121-1128, doi: 10.1016/j.ultrasmedbio.2012.02.026, indexed in Pubmed: 22542258.

74. Trehan SK, Lyman S, Ge Y, et al. Incidence of nerve repair following endoscopic carpal tunnel release is higher compared to open release in New York state. HSS J. 2019; 15(2): 143-146, doi: 10.1007/s11420-018-9637-1, indexed in Pubmed: 31327945.

75. Trybus M, Koziej M, Belka M, et al. The Polish version of the Boston Carpal Tunnel Questionnaire: Associations between patient-rated outcome measures and nerve conduction studies. J Plast Reconstr Aesthet Surg. 2019; 72(6): 924-932, doi: 10.1016/j.bjps.2018.12.032, indexed in Pubmed: 30611680.

76. Tulipan J, llyas A. Carpal tunnel syndrome surgery. Plast Reconstr Surg Glob Open. 2020; 8(3): e2692, doi: 10.1097/ gox.0000000000002692.

77. Tung T, Mackinnon S. Secondary carpal tunnel surgery. Plast Reconstr Surg. 2001; 107(7): 1830-1843, doi: 10.1097/00006534-200106000-00032.

78. Walker WC, Metzler M, Cifu DX, et al. Neutral wrist splinting in carpal tunnel syndrome: a comparison of night-only versus full-time wear instructions. Arch Phys Med Rehabil. 2000; 81(4): 424-429, doi: 10.1053/mr.2000.3856, indexed in Pubmed: 10768530.

79. Werner RA, Andary M. Carpal tunnel syndrome: pathophysiology and clinical neurophysiology. Clin Neurophysiol. 2002; 113(9): 1373-1381, doi: 10.1016/s13882457(02)00169-4, indexed in Pubmed: 12169318.

80. Wright AR, Atkinson RE. Carpal tunnel syndrome: an update for the primary care physician. Hawaii $J$ Health Soc Welf. 2019; 78(11 Suppl 2): 6-10, indexed in Pubmed: 31773104.

81. Wulle $C$. The synovial flap as treatment of the recurrent carpal tunnel syndrome. Hand Clinics. 1996; 12(2): 379-388, doi: 10.1016/s0749-0712(21)00321-8.

82. Yunoki M, Kanda T, Suzuki K, et al. Importance of recognizing carpal tunnel syndrome for neurosurgeons: a review. Neurol Med Chir (Tokyo). 2017; 57(4): 172-183, doi: 10.2176/nmc. ra.2016-0225, indexed in Pubmed: 28154344.

83. Zivkovic S, Gruener G, Arnold M, et al. Quality measures in electrodiagnosis: Carpal tunnel syndrome-An AANEM Quality Measure Set. Muscle Nerve. 2020; 61 (4): 460-465, doi: 10.1002/mus.26810, indexed in Pubmed: 31950523.

84. Żyluk A. The role of genetic factors in carpal tunnel syndrome etiology: A review. Adv Clin Exp Med. 2020; 29(5): 623-628, doi: 10.17219/acem/118846, indexed in Pubmed: 32407610.

85. Żytkowski A, Tubbs R, Iwanaga J, et al. Anatomical normality and variability: Historical perspective and methodological considerations. Transl Res Anat. 2021; 23: 100105 , doi: 10.1016/j.tria.2020.100105. 